Research article

\title{
Impact of culvert flooding on carnivore crossings
}

\author{
João Craveiro ${ }^{\mathrm{a}}$, Joana Bernardino ${ }^{\mathrm{a}}$, António Mira ${ }^{\mathrm{a}}$, Pedro G. Vaz ${ }^{\mathrm{b}, *}$ \\ ${ }^{a}$ Conservation Biology Unit, Department of Biology, Research Centre in Biodiversity and Genetic Resources, Pole of Évora (CIBIO-UE / InBIO), University of Évora. Mitra, \\ Évora, Portugal \\ ${ }^{\mathrm{b}}$ Centre of Applied Ecology "Prof. Baeta Neves" (CEABN-InBIO), School of Agronomy, University of Lisbon, Tapada da Ajuda, 1349-017, Lisbon, Portugal
}

\section{A R T I C L E I N F O}

\section{Keywords:}

Animal movement

Mitigation measures

Road ecology

Dry ledges

Passage efficacy

Wildlife corridors

\begin{abstract}
A B S T R A C T
Along many roads worldwide, drainage culverts are the only structures wildlife can safely use to cross. However, culverts inundate and can become unavailable to terrestrial fauna during rainy periods. We conducted a field study over wet and dry seasons in southern Portugal to assess the effect of culvert flooding on crossings by medium-sized carnivores. We set up track stations inside 30 culverts along intermediate-level traffic roads to evaluate complete crossings $(n=1211)$ and used mixed-effects models to quantify the effects. Carnivores were more likely to cross and crossed more frequently if the culvert had a natural dry pathway at the time of the crossing. Carnivores were also more likely to cross culverts with streams running through them. Moreover, culverts with flowing streams during the wet season were still more likely to be crossed during the dry season when the streams were dry. The significance of the difference in crossing rates between wet and dry seasons was species-specific. Our study reveals that flowing water and dry pathways jointly contribute to promoting crossings by this carnivore community. Culverts including streams may act as a continuation of riparian corridors, being incorporated into carnivores' movement routes. Our results lend empirical support to recommendations advising the implementation of dry pathways to provide crossing paths. Interventions to offset the transient impacts of water flooding in new or existing culverts can be a cost-effective solution promoting connectivity across roads allowing movement of individuals.
\end{abstract}

\section{Introduction}

Although roads increase habitat fragmentation, act as barriers to movement, and kill many animals (Grilo et al., 2015), much effort has been made to mitigate these effects. It is becoming increasingly common to include technically sound structures allowing safe animal road-crossings, especially along roads and highways (Clevenger and Waltho, 2000, 2005; Forman et al., 2003). Because fully adequate wildlife crossing structures are expensive (Ascensão and Mira, 2007; Glista et al., 2009), safe road-crossings commonly rely exclusively on drainage culverts designed for water flow (Delgado et al., 2018). Regrettably, these culverts inundate repeatedly becoming unavailable to most terrestrial fauna during rainy periods (Liu and Zhao, 2003; Grilo et al., 2010).

Culverts are primarily engineered to allow rainwater runoff and stream flow under the road and prevent flooding (Liu and Zhao, 2003). Culvert dimensions may be determined for an estimated return period of the maximal discharge (e.g., 50 years between occurrences) based on local climatological and hydrological characteristics (Schall et al., 2012). Notwithstanding, different groups of vertebrates regularly use drainage culverts worldwide (Dodd et al., 2004; Ng et al., 2004; Crook et al., 2013), including in Mediterranean areas (Yanes et al., 1995; Rodriguez et al., 1996; Clevenger et al., 2001; Mata et al., 2005), such as in southern Portugal (Ascensão and Mira, 2007; Grilo et al., 2008; Serronha et al., 2013; Villalva et al., 2013). Different species can show species-specific preferences for how the culvert is designed (Martinig and Bélanger-Smith, 2016).

Given their large home-ranges, low population densities, low reproductive rates, and dispersal needs, carnivores are particularly vulnerable to road impacts (Grilo et al., 2015). Carnivores forage and disperse across roads throughout their territory, increasing the likelihood of road encounters and car collisions (James and Stuart-Smith, 2000; Clevenger and Wierzchowski, 2006). Among medium-sized carnivores, the European badger (Meles meles) is a well-documented species in which $10-40 \%$ of mortality events in some populations may be due to roadkill deaths (van der Zee et al., 1992; Aaris-Sørensen, 1995; Clarke et al., 1998; Revilla et al., 2001). In southern Portugal, Grilo et al. (2009) estimate an annual roadkill rate of about 47 medium-sized carnivores $/ 100 \mathrm{~km} /$ year along $314 \mathrm{~km}$ of national roads. Noticeably, animal deaths may diminish on roads with implemented mitigation

\footnotetext{
* Corresponding author.

E-mail address: pjgvaz@isa.ulisboa.pt (P.G. Vaz).
} 